\title{
METATEATRO Y RETEATRALIZACIÓN EN FERMÍN CABAL*
}

\author{
Esther Ortas Durand**
}

\begin{abstract}
RESUMEN. El componente metateatral constituye un vector fundamental de la dramaturgia de Fermín Cabal. Este artículo aborda aspectos atingentes al aprovechamiento que Cabal realiza de dicho componente reflexivo para explorar la compleja relación entre la apariencia y la realidad. Los recursos utilizados por el autor varían desde el uso conscientemente exacerbado de la teatralidad en Tú estás loco, Briones y Vade retro!, a la multiplicidad de planos superpuestos de Esta noche gran velada o el teatro dentro del teatro en Caballito del diablo. Mostrando -y desvelando-tales apariencias y engaños ante el espectador, Cabal pone en cuestión las fórmulas del espectáculo dramático y de la vida cotidiana.
\end{abstract}

ABSTRACT. Metatheatre is a fundamental vector of Fermin Cabal's plays. This paper deals with aspects relating to the use made of this reflective element by Cabal in order to inquire into the complex relation between appearance and reality. Several resources are tapped by the playwright: the consciously exacerbated use of theatrical elements in Tú estás loco, Briones and Vade retro!, the multiplicity of superposed levels in Esta noche gran velada or the play within the play in Caballito del diablo. By displaying -and by resolving- these illusions and delusions in the presence of the spectator, Cabal calls in question the formulas of dramatic show and daily life.

Si el teatro de Fermín Cabal supone la construcción de una poética de lo cotidiano ${ }^{1}$, dirige además un enfoque crítico no sólo a la situación retratada en el texto dra-

* Recibido el 15 de marzo de 1993

** Licenciada en Filosofía y Letras (Sección de Filología Hispánica). Becaria de Investigación del Instituto de Estudios Altoaragones. C/. San Antonio M. ${ }^{a}$ Claret, $16,4 .{ }^{\circ} \mathrm{D}-50005$ Zaragoza.

1. Véanse las palabras de Cabal en Teatro español de los 80, Madrid, Fundamentos, 1985, p. 174; y las observaciones de Fernando Valls, "El teatro español entre 1975 y 1985", Las nuevas letras, núms. 3-4 (1985), p. 115. 
mático, sino también -y sobre todo- de los propios personajes ante el medio en que se mueven y la determinación de su identidad más profunda, en un descubrimiento de lo que permanece oculto bajo la propia apariencia ${ }^{2}$. Partiendo de esta línea de análisis, cabe plantearse el alcance y la función de lo metateatral en su dramaturgia, en un amplio sentido que incluye desde el teatro dentro del teatro hasta la presentación de elementos conscientemente teñidos de exacerbada teatralidad ${ }^{3}$.

Tales usos de la metateatralidad hunden sus raíces en la tradición del theatrum mundi y en el teatro barroco ${ }^{4}$, al tiempo que entroncan directamente con ese impulso reteatralizador del siglo XX que incide en la reflexión sobre la propia naturaleza del teatro y sobre la compleja relación entre la realidad y la ficción ${ }^{5}$. Esta misma veta autorreflexiva se manifiesta en coetáneos españoles del autor como Alonso de Santos o Sanchis Sinisterra, cuya trayectoria y formación, al igual que la de Cabal, debe vincularse a grupos teatrales independientes 6 .

\section{De Tú estás loco, Briones a Vade retro!}

Fermín Cabal aprovecha las posibilidades de la exageración de la teatralidad y su uso plenamente consciente desde Tú estás loco, Briones, donde potencia el componente humorístico o farsesco, a la vez que refleja los difusos contornos de la dialéctica locura-cordura modificados continuamente por Faustino Briones.

2. Cfr. Fermín Cabal, en Teatro español de los 80, p. 176: "El teatro ofrece la posibilidad de mostrarle a la gente que no somos como creemos ser".

3. Para un resumen de los diversos aspectos de la metateatralidad, véase Patrice Pavis, Diccionario del teatro. Dramaturgia, estética, semiología, Buenos Aires: Paidós, 1984, s.v. metateatro y (re)teatralización. Varias monografías abordan las implicaciones teóricas del tema; entre ellas destacan la fundadora de Lionel Abel, Metatheatre. A New View of Dramatic Form, New York: Hill \& Wang, 1963 -que me ha sido imposible consultar directamente-; la de Manfred Schmeling, Métathéâtre et intertexte: aspects du théâtre dans le théâtre, Paris, Lettres Modernes, 1982; y la de Richard Hornby, Drama, Metadrama and Perception, Lewisburg: Bucknell University Press, 1986.

4. Véanse, desde diferentes perspectivas, Emilio Orozco Díaz, El teatro y la teatralidad del Barroco (Ensayo de introducción al tema), Barcelona: Planeta, 1969; Katarzyna Mroczkowska-Brand, Overt Theatricality and the "Theatrum Mundi" Metaphor in Spanish and English Drama, 1570-1640, Michigan: UMI, 1985; y Alva V. Ebersole, Sobre arquetipos, simbolos y metateatro, Valencia: Albatros, 1988.

5. Véase Jean-Jacques Roubine, Introduction aux grandes théories du théâtre, Paris: Bordas, 1990 , pp. 125 y $167-169$.

6. $C f r . M^{a}$ Francisca Vilches de Frutos, "El teatro español en los 80 . Tendencias predominantes (I)", Insula, 456-457 (1986) pp. 14-15. Para los autores citados, véanse respectivamente Fermín Tamayo y Eugenia Popeanga, "Introducción" en José Luis Alonso de Santos, Bajarse al moro, Madrid, Cátedra, 1991, especialmente p. 14; y Manuel Aznar Soler, "Grenztheater als Metatheater. José Sanchis Sinisterras Teatro Fronterizo: von Naque bis ;Ay, Carmela!", en Spanisches Theater im 20. Jahrhundert. Gestalten und Tendenzen, ed. de Wilfried Floeck, Tübingen, Francke, 1990, pp. 233-255, e "Introducción" en José Sanchis Sinisterra, Naque o de piojos y actores. ;Ay, Carmela!', Madrid: Cátedra, 1991, especialmente p. 39, n. 53. 
El recurso se encuentra en la misma designación de los personajes, connotada irónicamente7: "Faustino Briones" sugiere el contraste del nombre propio y su componente diminutivo frente a los desmesurados bríos del aumentativo plural del apellido; Pilar incorpora ya en su onomástica valores de hispanidad y tradición; sin olvidar a Onésima. Asimismo, el sintagma "Sor Angustias del Pesebre" (TELB, p. 25) $)^{8}$, incluye un complemento ridiculizador y poco adecuado al nombre.

Mención aparte merece el Dr. Borrego, con un apellido de resonancias negativas, funcional en cuanto caracteriza perfectamente su comportamiento político. En los inicios de la obra, Sor Angustias comenta a Faustino que Borrego es "del Régimen (...). Si alguna vez entra en su despacho verá una fotografía del doctor con Franco... a la derecha de la mesa" (TELB, p. 28); pero el médico trata ahora de borrar las huellas de su filiación, inconvenientes para la situación de transición democrática, en un proceso de ocultamiento del pasado desenmascarado precisamente por Faustino cuando le pregunta en su despacho por la fotografía "que estaba ahí. Todavía se ve el recuadro que ha dejado en la pared" (TELB, pp. 51-52). Además, la capacidad alusiva del apellido adquiere nuevas dimensiones en el ficticio diálogo entre Briones y el Retrato del que surge la voz de Franco que insta al protagonista: "iPues apacienta mis borregos!" (TELB, pp. 58 y 59 ).

Por otra parte, una de las constantes que caracterizan la obra del autor leonés es la presencia de la dialéctica realidad-ficción en los diversos niveles de construcción dramática. Desde el principio, Faustino Briones afirma y reclama el reconocimiento de los hechos que acompañan su reclusión:

BRIONES. ¿Así que no estoy detenido? Entonces, ¿por qué no me dejan ir a mi casa? La celda en la que me han encerrado me la he inventado yo, ¿verdad? ¿Y esta señal que tengo en el cuello (Se la señala) es también una ilusión mía?

(...)

¡Ustedes son los que hacen la violencia! ¿Acaso no me han traído aquí por la fuerza y sin mediar ningún tipo de explicaciones? ¿O es que estoy loco y no sé lo que digo? (TELB, p. 22)

Briones experimenta una tensión mental entre el deseo de que su encierro sea un mal sueño y la realidad palpable; todo ello se manifiesta con la desmesurada gestualidad de un personaje enfrentado a unas situaciones que lo desbordan:

7. Jesús Rubio, "Del teatro independiente al neocostumbrismo", Hispanistica XX, núm. 7 (1989), p. 199, analiza este aspecto para los casos de Faustino, Pilar, Onésima y Borrego.

8. Empleo las siguientes abreviaturas: Tú estás loco, Briones [TELB], Fuiste a ver a la abuela??? [FVA], Vade retro! [VR], Esta noche gran velada [ENGV], y Caballito del diablo [CD]. Las citas se refieren respectivamente a Fermín Cabal, Tú estás loco, Briones. Fuiste a ver a la abuela??? Vade retro!, Madrid: Fundamentos, 1987; y iEsta noche gran velada! ¡Kid Peña contra Alarcón por el título europeo! Caballito del diablo, Madrid: Fundamentos, 1989. 
BRIONES. ¡No es posible! No, no puedo creerlo... Es una pesadilla ¡Tiene que ser una pesadilla! (Se da de bofetadas).

Sor. (Sujetándole) Vamos, cálmese... ¡Cálmese!

BRIONES. No, no, estoy soñando. ¡Despierta, Briones, despierta! ¡Esta mujer no existe, es un fantasma, mira! (Pellizca a la monja que da un respingo y le da una bofetada)

(...)

BRIONES. Entonces... es real. (TELB, pp. 25-26)

Así pues, en la mente de Briones quiere perpetuarse un modelo de vida que ya no existe, se pretende continuar lo definitivamente acabado de manera ficticia ${ }^{9}$; esto precisamente llevará a Faustino a la locura, a la confusión de los límites entre lo real y lo imaginario que aquélla implica, al tiempo que el gesto desmesurado y la teatralidad exacerbada coadyuvan a la expresión del universo ahora ficiticio en el que ha quedado el empleado de Sindicatos. Incluso él mismo versifica -y por tanto literaturiza- esa escisión interna entre la realidad anterior de la que no ha sabido salir y la nueva realidad no asumida, en la búsqueda de su identidad profunda y auténtica (TELB, p. 56).

No obstante, el espectador asiste al proceso de unos personajes que evolucionan -también Angustias se transforma-; partiendo de esta idea, se comprende mejor el cambio del Faustino que no acierta a interpretar correctamente los datos que percibe y aquél que finge conscientemente en su beneficio. En el primer caso, baste recordar cómo Briones cree ver en Sor Angustias a "la Virgen María", "Mater Amantísima", "Virgo venerada" y "Virgen Serenísima" (TELB, p. 40), en una escena donde la ficción generada por el protagonista hace que éste represente una actitud adecuada ante la Virgen al arrodillarse e invocarla, pero desmesurada frente a la monja que pretende inyectarle un calmante y le pide que se baje los pantalones. Así, el espectador de la obra percibe unos signos teatrales, los de la monja y la inyección, lo que contrasta con la visión del paciente; en dicha divergencia y en la actitud inadecuada respecto a lo contemplado por el público reside el efecto humorístico de la escena, fruto de la distancia ${ }^{10}$.

En el mismo contexto podemos considerar la escena en que Briones se irrita al conocer el embarazo de su hija y pretende enfrentarse con el novio de la muchacha:

BRIONES. (...) ¿Que venga aquí le digo! Inmediatamente... Y que pida perdón de rodillas... (Al verle tan excitado la señora BRIONES va hacia la puerta para llamar a la monja, y al abrir, el LOQUERo, que escuchaba tras la puerta,

9. June Schlueter, Metafictional Characters in Modern Drama, New York: Columbia University Press, 1979, p. 29, analiza cómo, frente a la vida, la ficción transciende la sucesión del tiempo en tanto que permite congelar un diseño que perdura inmutablemente.

10. $\mathrm{M}^{\mathrm{a}}$ del Carmen Bobes Naves, Semiología de la obra dramática, Madrid: Taurus, 1987, pp. 92-93, estudia el problema del humor teatral basado en los contrastes sígnicos y de formantes. 
rueda por el suelo y queda situado frente a FAUSTINo de rodillas) ¡Ah, ya estás aquí! Así me gusta, de rodillas y pidiendo clemencia. ¡Silencio!, aquí sólo se habla cuando yo lo digo. ¿Quieres a mi hija, verdad? Pues la tendrás, pero no sueñes que me vas a sacar un duro... (TELB, pp. 38-39)

El mecanismo generador de la errónea asignación de identidad que lleva a cabo Faustino se desencadena por la coincidencia entre la situación en que desea colocar Briones al novio y la posición en que queda el loquero tras su caída. Así pues, la clave de la situación se encuentra en la plasticidad del cuerpo caído arrodillado y la proximidad a Faustino, producto de la modificación repentina en la distribución material de elementos del espacio dramático ${ }^{11}$; esto ocasiona la ficticia interpretación del protagonista frente a los demás personajes y al público de la obra.

El gesto y el desplazamiento del loquero provocan por sí mismos la reacción de Briones, reemplazando a la palabra ${ }^{12}$; ésta era elemento fundamental en la escena considerada anteriormente, donde lo visual y sonoro actuaban parejamente en el paciente que escuchaba y veía "esa voz... esos mantos... no hay duda... ¡Es la Virgen María!" (TELB, p. 40). Asimismo, la correlación apreciable entre el arrodillamiento del loquero a los pies del paciente y el de éste ante Angustias contribuye a completar el componente kinésico y espacial que articula toda la situación.

Cuando la identidad de Faustino haya encontrado el nuevo cauce de afirmación del amor a Angustias, quien para él es "lo más real" que conoce (TELB, p. 45), Briones manipulará la realidad conscientemente. Así ocurre tras la escena de los teatrales y fallidos intentos suicidas del protagonista, que dan lugar al desmayo de éste; tal circunstancia será aprovechada como treta para conseguir el contacto físico con la monja:

Sor. ¡Faustino! ¿Se ha hecho usted daño? (FAUSTINo se hace el muerto) ¡Dios mío! ¡Qué terrible accidente! ¡Rodolfo, Rodolfo, venga inmediatamente!

11. Yuri Lotman, Estructura del texto artístico, Madrid: Istmo, 1978, p. 262, analiza la función del espacio artístico. Para una casuística de los movimientos espaciales, véase $\mathrm{M}^{\mathrm{a}}$ del Carmen Bobes, Semiología de la obra dramática, pp. 243 y 244. Anne Ubersfeld, Semiótica teatral, Madrid, Cátedra, 1989, pp. 133 y ss., observa el cambio de las cualidades de un signo en relación con otros según el espacio en que se ubique; y $c f r$., en general, A. Patricia Trapero, Introducción a la semiótica teatral, Palma de Mallorca: Prensa Universitaria, 1989, pp. 56 y 93. Una buena síntesis sobre las posibilidades de la proxémica en Umberto Eco y André Helbo, "L' oracle et la comédie", en VV. AA., Sémiologie de la représentation, Bruxelles: Editions Complexe, 1975, pp. 39-40.

12. Luciano García Lorenzo, "Elementos paraverbales en el teatro de Buero Vallejo", en VV.AA., Semiología del teatro, Barcelona: Planeta, 1975, pp. 107-108, recoge la distinción de Larthomas entre gestos de acompañamiento, prolongación y reemplazantes, concepto este último que adapto al estudio de los movimientos elocuentes por sí. Y véase Umberto Eco, La estructura ausente. Introducción a la semiótica, Barcelona: Lumen, 1986, pp. 19-21 y 279-280, para las vertientes convencionales y productivas de la kinésica y el movimiento. Una espléndida síntesis sobre la función de la fisicidad teatral en Gianfranco Bettetini, Producción significante y puesta en escena, Barcelona: Gustavo Gili, 1977, pp. 102 y ss. 
El corazón late (Le da un masaje. FAUSTINo se queja). Parece que no respira bien (Se pone a hacer el boca a boca. Entra el LOQUERO).

(...)

El señor Briones está inconsciente, Rodolfo, ¡qué desgracia!... Le estoy haciendo el boca a boca.

LOQUERO. Déjeme, hermana, lo haré yo (Va hacia BRIONES y le coge pero éste se reanima).

BRIONES. Ya me encuentro mejor. ( TELB, p. 65)

Esta vez el propio Faustino inicia la ficción y la concluye bruscamente cuando deja de producir el efecto esperado. El suicida, en funciones de autor y actor de su representación, finge haber muerto para provocar la reacción de Angustias, pero trunca su actuación cuando un personaje -el loquero- irrumpe de modo imprevisto y modifica la pieza. Angustias cree auténtica la simulación del enfermo, de manera que es ella quien yerra y, en tanto público en su posición privilegiada de interpretante ${ }^{13}$, entiende como cierta la gravedad de su enamorado; todo ello se produce en un segundo ámbito de ficción dentro del espacio dramático.

No obstante, el alcance de las relaciones entre lo real y lo no real subyace de modo paralelo en Vade retro!, donde la multiplicación de los niveles de equívoco lingüístico o situacional configura una red mutua de falsedad en la que la apariencia surge de lo engañoso. Baste recordar la significativa escena en que Lucas propicia una premeditada confusión sobre la naturaleza de los colmillos que adornan el cuarto hasta arrastrar finalmente a Abilio al error del cual había partido el joven sacerdote ( $V R$, pp. 129$130)$; así lo muestra el diálogo, con una estructura en la que la repetición de las palabras por uno y otro genera un equívoco capaz de sacar al interlocutor de su posición inicial. Mediante el juego de la inadecuada identificación del objeto y de la posterior negación de sus palabras durante el citado diálogo, Lucas crea una ficción: representa el papel de quien yerra y debe ser corregido por Abilio; a la vez, orienta la acción con el fin de que su compañero se convierta en el personaje que se equivoca, propiciando así un intercambio de actuaciones ${ }^{14}$.

Las mentiras más aparentes para el espectador de este tejido de engaños son las del padre Abilio, pero éste las desvela enseguida, en una clave modificada luego súbitamente ante la efectista noticia del acierto de la quiniela; por el contrario, Lucas se mantiene en su ficción aun cuando ni Abilio ni el propio público de la representación

13. Para las implicaciones de esta relación, véanse Pavel Campeanu, "Un rôle secondaire: le spectateur", en VV.AA., Sémiologie de la représentation, p. 103; y André Helbo, Teoría del espectáculo. El paradigma espectacular, Buenos Aires: Galena, 1989, pp. 25 y 36. Manfred Schmeling, op. cit., p. 6, establece los juegos perspectivísticos en los que entran los asistentes a la representación en estos casos.

14. Phyllis Zatlin, "El (meta)teatralismo de los nuevos realistas", en La cultura española en el postfranquismo. Diez años de cine, cultura y literatura en España (1975-1985), ed. de Samuel Amell y Salvador García Castañeda, Madrid: Playor, 1988, p. 128, señala el procedimiento metateatral por el que el papel de los actores puede funcionar como un papel dentro de otro, pero no extiende más su análisis. 
puedan sospechar en qué sentido y con qué fin. En el entramado de juegos donde un personaje proyecta varios papeles a la vez, una ilusión solapa a otra y el propio estatuto de lo real queda en entredicho' ${ }^{15}$.

Por otra parte, la exageración gestual constituye un cauce de la señalada tensión ficción/realidad que se observa en la pelea entre los protagonistas de Vade retro!; sin embargo, dicha exacerbación de gestos y movimientos, conjugada con una concentración de elementos que destacan lo ficticio, resulta especialmente productiva en $T u ́$ estás loco, Briones. A continuación, serán considerados tres momentos que incorporan dichos recursos de teatralidad y marcan hitos en la actitud de Faustino.

En el ataque de Faustino a Quintanilla, ambos personajes teatralizan sus acciones y entran en el juego de un ficticio asesinato, con el cual Briones defiende sus ideales frente a quien los ha vivido como "comedia" (TELB, p. 43):

BRIONES. Te agradezco el regalo, pero espera, te voy a dar algo a cambio (Abre la maleta y saca un enorme cuchillo trucado) ¿Qué te parece? Ven, no tengas miedo... (Va hacia él y Quintanilla le ofrece el pecho) Toma, cabrón, toma, toma... (Le acuchilla varias veces. Quintanilla rie a lo bestia)

QuinTANILlA. ¿Has terminado? Mejor harías pegándote un tajo en ese cuello de burro que tienes. Adiós, chico, hasta más ver...

(...)

SoR. ¿Qué hace? Ha roto el termómetro... (El cuchillo de Faustino es ahora un termómetro). (TELB, pp. 43 y 44)

Parece lícito calificar la escena de granguiñolesca por la muñequización gestual y objetual ${ }^{16:}$ la marioneta vital que es Briones afronta una situación política y familiar que lo desborda accionando con profusión y desmesura.

Quintanilla no actúa como amenazado, sino que ríe y trata con dureza a su compañero, anulando cualquier interpretación trágica del acto de Faustino. Más significativo resulta que la propia arma sea falsa y carezca de efectividad al estar trucada; sobre este primer plano que ya implica teatralidad se desvela la apariencia de un cuchillo que se convertirá en termómetro ${ }^{17}$. El efecto se amplía en una caja china de múltiples niveles ${ }^{18}$.

15. Para la productividad metadramática de dicha multiplicidad de papeles en un mismo personaje, véase Richard Horbny, op. cit., pp. 67 y ss.; y cfr. Anne Ubersfeld, op. cit., p. 37.

16. Cfr. Jesús Rubio, art. cit., pp. 198- 199. Para el empleo de la mímica y kinésica en el teatro coetáneo al de Cabal, véase $\mathrm{M}^{2}$ Francisca Vilches de Frutos, "El teatro español en los 80...", p. 14.

17. Para la relación entre los formantes semánticos y su significado, $\mathrm{M}^{\mathrm{a}}$ del Carmen Bobes, Semiología de la obra dramática, p. 81, y "La semiología del teatro: los signos de la representación", en Estudios de semiología del teatro, Valladolid: Aceña-La Avispa, 1988, especialmente pp. 212 y 221.

18. Véase Lucien Dällenbach, Le récit spéculaire. Essai sur la mise en abyme, Paris: Seuil, 1977; y cfr. Mieke Bal, "Mise en abyme et iconicité, Littérature, 29 (1978), pp. 116-128, que profundiza los contactos entre la puesta en abismo ficcional y la reflexión sobre el mismo proceso literario. 
Las otras dos escenas ofrecen una realidad teatral desdoblada al aparecer una secuencia soñada o imaginada ${ }^{19}$. La imagen de Faustino amarrado con los brazos en cruz enmarca el diálogo entre el paciente y el retrato; la última acotación subraya el cambio de plano respecto al resto de la acción:

(Oscuro)

(Luz sobre FAUSTINo tal como le dejó atado el LOQUERO). (TELB, p. 59)

Incluso Briones marca la transición de lo soñado a lo real:

Briones. (Aturdido) No, no, ¡ha sido sólo un sueño! (A FRANCO) ¡Diles que ha sido sólo un sueño! (TELB, p. 60)

La acción se organiza en torno a Faustino y a la voz que surge del iluminado "(...RETRATO, un bajorrelieve accionado por varillas $) "$ (TELB, p. 58). De la luz y el movimiento de este significativo objeto parte la teatralidad y el efectismo visual que culminan en la desmembración y ulterior unión del brazo del protagonista:

BRIONES. ¡Arriba España! ¡Aghhh! (Se pone de pie y de la cabecera de la cama queda colgando lastimosamente un brazo desgarrado. Se retuerce de dolor)

(...)

Retrato. ¡Pues apacienta mis borregos! Y ahora acércate... sana, sana, culito de rana, si no sanas hoy sanarás mañana... ¡ya está!

BRIONES. (Sacando el brazo de nuevo) ¡Milagro! (TELB, p. 58)

Las alusiones bíblicas son patentes tanto en las palabras del dios que encomienda a su hijo la dirección pastoral del rebaño, como en la teatralización de la escena donde contemplamos a Briones crucificado. En general, el mecanismo paródico se basa en el desnivel entre el modelo y la aplicación de tales palabras sobrenaturales a un ser histriónico como Faustino; asimismo, los efectos mecánicos del retrato que acciona o del brazo separado distancian y ponen de manifiesto lo artificioso de esa escena ficticia dentro de la obra teatral. Así, en el espacio de la imaginada conversación se exacerba la ficcionalización y la capacidad de manipulación de lo que ocurre en el escenario para hacer ver lo que no sucede, o para que suceda lo imposible en el terreno real.

Ante el espejo, de tradicional poder desvelador y perspectivístico, Faustino teatraliza su reflexión mediante el diálogo con Sosias ${ }^{20}$. Entonces se consuma el cambio del

19. Véase Manfred Schmeling, op. cit., p. 8. En Vade retro! vuelve a emplearse el sueño, pero en tanto generador de un espacio dramático en el cual Abilio ejerce como espectador de las fantasías de Lucas ( $V R$, pp. 157-158); el mecanismo es paralelo al estudiado en Tirso de Molina por Francisco Ayala, "Erotismo y juego teatral en Tirso", Insula, 214 (1964), p. 7.

20. Sobre la tradición de esta figura como participante en la representación que ocupaba el lugar de otro personaje, véase la síntesis de Patrice Pavis, op. cit., s.v. sosia. 
protagonista: el nuevo Briones reniega del anterior, que es "un crío" y "una víctima", usada y tirada "como un trasto viejo" (TELB, p. 68); avanzada la escena, Briones lo tilda de "fantasma" (TELB, p. 70), atribuyéndole un estatuto irreal que reafirma a Faustino en su decisión de abandonar todos aquellos ideales franquistas y el pasado que Sosias encarna. La disputa final subraya y culmina el carácter ficticio con una fuerte dosis de espectacularidad que reteatraliza la situación dramática:

SOSIAS. ¡Canalla! (Se echa sobre él y pelean. FAUSTINO le arroja a la caja del espejo. El SosIaS desaparece). (TELB, p. 71)

El propio Briones rompe la ficción; se incorpora a una realidad renovada cuyo sentido reside en la ruptura con el pasado -familia, trabajo- y el abandono de las convenciones. Sin embargo, la pelea final con Campos -de nuevo un recurso de teatralidad- acaba con la muerte de Faustino, efectista y melodramática ${ }^{21}$.

\section{Esta noche gran velada}

Si en Tú estás loco, Briones, los elementos farsescos 22 de marcada teatralidad servían para plantear la relación entre apariencia y realidad, Cabal busca otros referentes genéricos en Esta noche gran velada, cuyo sustrato argumental y temático es el mundo cinematográfico. Se recrea el ambiente mafioso de las películas de boxeo ${ }^{23}$, con sus personajes característicos: el púgil sonado (Sony), el representante que amaña las peleas (Mateos), el boxeador que duda si aceptar o no (Kid), o el jefe del negocio de las apuestas (Achúcarro), paradójicamente encarnado en la representación de la obra por un enano ${ }^{24}$. Asimismo, la escenografía del montaje madrileño mostraba el vestuario de Kid lleno de fotos de películas boxísticas ${ }^{25}$.

21. Anne Ubersfeld, op. cit., pp. 106-107, ha estudiado la carga de teatralización comportada por el uso de elementos codificados en la tradición. Por su parte, Cabal, en Teatro español de los 80 , p. 168, comenta cómo varió el final de la obra, en el cual "ataban a Briones a la cama del hospital y acababa gritando:¡cabrones! ¡soltadme! ¡quiero salir!”; no obstante, editó el final primigenio al considerarlo más sólido para la pieza.

22. En palabras del autor, "con Fuiste a ver a la abuela??? me planteé definitivamente abandonar la farsa" (Teatro español de los 80, p. 172); "yo he ido evolucionando, si quieres, de la farsa a la comedia dramática, pero siempre dentro de unos parámetros realistas" (José Luis Vicente Mosquete, "Caballito: Fermín Cabal liquida existencias", El Público, 21 (1985) p. 37).

23. Véase Miguel Medina Vicario, “A propósito de un texto de Fermín Cabal: ;Esta noche gran velada...!", Primer Acto, 201 (1983) p.93; y Alberto Fernández Torres y Moisés Pérez Coterillo, "Quince y muchos más títulos de autor para una crónica del teatro de la transición", Cuadernos El Público, 9 (1985), p. 12.

24. Aunque nada se dice en las acotaciones al respecto, el montaje inicial de la obra contó con un actor de dichas características, cfr. sólo la fotografía recogida por Francisco Alvaro, El espectador y la crítica (El teatro en España en 1983), Valladolid, Francisco Alvaro, 1984, p. 89.

25. La acotación inicial indica la presencia de "fotos de Boxeadores y carteles que anuncian combates ya perdidos" ( $E N G V$, p.9); y $c f r$. la fotografía citada supra, n. 24. Phyllis Zatlin, art. cit., p. 129, recuerda que "el montaje de Manuel Collado reforzó el aspecto peliculero del texto. Fotos de películas boxísticas decoraban el Teatro Martín". 
Ya herido, el campeón europeo extrae de su memoria de espectador cinematográfico una escena capaz de unir pasado y presente: "El mundo puede derrumbarse sobre mí como en aquella película de Sansón que vimos juntos..." (ENGV, p. 77). De esta manera, el universo del celuloide determina la personalidad de Enrique a la vez que Kid es en sí un personaje del cine.

Marina ha trabajado en "alguna película" ( $E N G V$, p. 51) y la novia de Kid quiere "ser artista" (ENGV, p. 50); pero la carrera de la primera sólo la convierte en amante de Angel Mateos, camino de prostitución por el cual parece empezar a transitar Ana, quien ha roto su relación amorosa con el púgil para unirse a su representante artístico. La aspiración al triunfo en el cine se revela como un anhelo en el cual las promesas de éxito encubren el interés sexual.

Los planos de la mendacidad se despliegan en todos los niveles. En el marco general de la pieza, Kid se enfrenta a la participación en un combate amañado que muestra también el juego sucio dominante en una vida definida por el "engaño, engaño y ¡engaño!" ( $E N G V$, p. 29). La única diferencia aparente entre ambos ámbitos de falsedad reside en que la reconciliación del boxeador y su novia no puede ser propiciada por Mateos, cuyo poder manipulador parece en este momento reducirse al boxeo ( $E N G V$, p. 21); sin embargo, los amaños desbordan el terreno meramente pugilístico:

Mateos. ¿Y de qué quiere triunfar tu novia?

KID. De artista, Don Angel, como todo el mundo. Desde que ganó aquel concurso de misses, no hay quien se lo saque de la cabeza... ¿Se acuerda del concurso que le digo?

MATEOS. ¡Humm! Miss Zamora... ¡No me voy a acordar! Me costó buena pasta... Te costó a ti, porque el dinero era tuyo... ¡Y ahora ya ves! Lo que son las cosas...

(...)

KID. ¡Entonces usted le compró el título!

MATEOs. Lo compramos. Si lo quieres ver así. (ENGV, p. 30)

Así se prolonga el sucesivo desvelamiento de falsedades desencadenado por la carta de Ana. La ironía es tan desgarradora como múltiple la incrustación de niveles en la obra teatral: la traición de la joven proviene de un éxito real, pero que se descubre basado en la manipulación de Mateos; esta falacia le lleva a la ficción de ser Lola Candelas. Por otra parte, Ana decide volver con su novio al saberlo campeón europeo; sin embargo, éste ya ha sido castigado precisamente por romper el acuerdo e ir en busca de la verdad -general y personal- luchando "sin trampa ni cartón" (ENGV, p. 65).

Kid yerra al discernir lo verdadero y lo fingido en su vivencia apasionada de los problemas de Nieves, que le empujan a luchar por el título mundial; a la vez, desconfía equivocadamente de la veracidad de la fuerte apuesta de Sony por su victoria y la interpreta como una treta para convencerlo de que combata. 
En esta línea de análisis se impone considerar los dos momentos claves en la metateatralidad de la obra: la representación de Mateos del papel de la madre del boxeador, y la conversación entre éste y Marina del inicio del acto segundo. En el primer caso, don Angel intenta convencer a Kid para que no abandone la pelea arguyendo el sufrimiento que ello producirá a su madre, los cuchicheos de las vecinas y la crueldad de los niños del pueblo. La descripción de Mateos se torna representación teatral con la cual propiciar una ilusión de realidad recreando un personaje ${ }^{26}$, con la pretensión de modificar la postura del boxeador:

MATEOs. Pues piénsalo, hombre... Imagínate la escena. Tú acabas de llegar a casa (Le da la bolsa de deporte) con el equipaje en la mano. Y ella sale al viejo zaguán a recibirte... ¿ Tenéis viejo zaguán, no? Siendo de pueblo... Entras y te encuentras con ella. ¿Qué haces? (ENGV, p. 45)

En el arranque de la escena, Mateos pretende articular el discurso y la dramatización del mismo del modo más verosímil posible para alcanzar su propósito. Así pues, intenta introducir a Kid en su mismo espacio y nivel escénico al darle la bolsa, objeto que sirve para adecuarlo a su papel de recién llegado de un viaje; sin embargo, el púgil no se sume en el plano ocupado por su representante y se mantiene como público ${ }^{27}$, en una distancia crítica que le permite corregir los defectos de la actuación de Mateos:

MATEOS. Sí, qué haces... Yo soy tu madre.

KID. No puede ser, Don Angel.

Mateos. ¿Por qué no?

KID. Mi madre no fuma.

MATEOs. Es un ensayo, Kid, no te preocupes de los detalles. (ENGV, p. 35)

Angel Mateos parece renunciar a la perfecta correspondencia entre la realidad y la ficción que presenta; no le interesa la equivalencia exacta, sino impresionar a Kid lo bastante como para influir en su decisión. Pero el púgil entra en el juego dramático desde el principio: por un lado, en el diálogo nunca se dirige a su madre sino a don Angel; por otro, continúa interrumpiendo la melodramática interpretación de su protector una y otra vez, señalando sus errores en las palabras y en las acciones (ENGV, p. 36).

26. Richard Hornby, op. cit., pp. 73-74, ha estudiado que recreaciones como ésta -voluntariamente realizada por don Angel- contienen una fuerte carga metateatral, capaz de generar un efecto irónico interno en el estatuto del personaje dentro de la obra y una reflexión sobre la misma condición humana. Para la relación entre realidad, ficción y signo teatral que finge no serlo, véanse Umberto Eco y André Helbo, "L'oracle et la comédie", pp. 34-35; y June Schlueter, op. cit., pp. 24 y 40.

27. Umberto Eco, Obra abierta, Barcelona: Planeta, 1985, p. 66, señala las consecuencias de tal actitud activa del espectador. 
Cuando el boxeador comienza a desempeñar su personaje de hijo que vuelve a casa, aquel criticismo se torna fluida comunicación con la madre, en la cual el hijo domina la situación y obliga constantemente al autor que es Mateos a aplicar nuevas estrategias ${ }^{28}$ para arrastrar a Kid a su terreno: combatir.

KID. Que le he dicho a Don Angel que me venía para casa y que no iba a

MAteos. Bueno, hijo, pues me da una alegría... ¿Y cómo se lo ha tomado?

KID. ¿Don Angel?

MATEOS. Sí, Don Angel... El, que es como un padre para ti, ¿cómo se lo ha tomado?

KID. Pues, al principio mal. Dijo: éste me va a querer hacer alguna jugarreta... Pero luego no, me ha dado unos consejos y todo...

Mateos. Vaya, hijo, mira qué amable... Qué hombre más considerado... Para que vayas diciendo por ahí que si esto que si lo otro...

KID. Pero, madre, si ha sido usted siempre la que ha echado pestes de Don Angel... ¡Nunca le ha podido ver!

MATEOS. No exageres, si apenas nos conocemos...

KID. Eso es lo que yo le decía. Pero a usted se le atragantó en la garganta como una espina. ¿No decía que tenía cara de lagarto? (ENGV, p. 37)

El boxeador puntualiza los equívocos del otro sin salir de la ficción de la conversación materno-filial, a diferencia de lo que sucedía anteriormente. La complejidad del solapamiento de niveles aumenta con la oposición frontal entre la auténtica actitud de la madre hacia Mateos y la falsa personalidad materna recreada por éste: por boca de Kid, la realidad invade y modifica la ficción; entonces, don Angel hace cambiar de opinión a su personaje para que su fingimiento suplante a dicha realidad.

Este teatro en el teatro de Esta noche gran velada muestra a dos personajes desempeñando a su vez dos papeles distintos, desarrollados en otro espacio y otro tiempo con el único auxilio de la palabra, sin huella escenográfica alguna al respecto; al mismo tiempo, manifiesta las fallas del intento mimético de reproducción exacta de la realidad en el teatro ${ }^{29}$.

La salida del ámbito de la escena representada se origina por idéntico mecanismo al señalado en su inicio: la corrección que Kid hace de los errores de la representación de Mateos dirigiéndose directamente a éste. Finalmente, don Angel también abandona la representación y vuelve a juzgar a la madre en tanto ser auténtico y tercera persona:

28. André Helbo, Teoría del espectáculo..., p. 139, considera el problema del cambio de estímulos desde el punto de vista teórico.

29. Un planteamiento renovado sobre la mímesis como caracterizadora del género teatral puede verse en Richard Hornby, op. cit., pp. 13-28, 99 y 105-106 
KID. Don Angel... ¡Mi madre qué sabe de contratos!

MATEOs. Tu madre sabe más que lepe. Mira esta firma, ¿de quién te crees que es? (Se la muestra) Rosario García, ¿no te suena? (...) Y encima dice que tengo cara de lagarto. Yo podría decir otras cosas y me las callo.

KID. ¡Yo esta noche no peleo, ni con contrato ni sin contrato! (ENGV, p. 39)

El cambio de actitud del púgil está determinado por su conversación con Marina en el segundo acto, durante la cual se aproxima afectivamente a la mujer, convertida en confidente de los problemas sentimentales del boxeador, y relata una pesadilla premonitoria del final de la obra ( $E N G V$, p. 49). La unión entre ambos personajes se acrecienta mediante el roce de sus manos, la simultaneidad de sus risas, o la consideración de Mateos como un "liante" y "tramposo" (ENGV, p. 51); dicho proceso anímico culmina con el despojo de sus nombres profesionales ficticios y su sustitución por los auténticos, tras el tuteo previo:

\section{MARINA. Ya me extrañaba, Kid.}

KID. No me llames así. Llámame Enrique. Ese es mi verdadero nombre: Enrique García Vinuesa. Kid Peña se terminó.

Marina. Entonces llámame Nieves. Nieves Pérez Fortes. A mi representante no le gustaba. Decía que era muy frío.

KID. Es un nombre estupendo. Un nombre puro y limpio. Como tu mirada. Tienes una mirada que... no sé... Uno sabe que se puede confiar en ti, aunque seas la novia de Don Angel. (ENGV, p. 53)

El nombre falso queda a un lado, pues en una relación sincera sólo cabe la identidad más profunda y auténtica ${ }^{30}$; este desvelamiento potencia el aprecio de Enrique por Nieves hasta alcanzar una renovada fe, capaz de impulsarlo a abandonar la máscara del Kid Peña perdedor y asegurar la felicidad de la novia de don Angel combatiendo. No obstante, el boxeador duda previamente de las pretensiones de Nieves (ENGV, pp. 50 y 52), e incluso la acusa de manipularlo para cambiar su decisión de no pelear:

KID. ¡Maldita sea mi estampa! ¿Qué es lo que quieres de mí? ¿Que me eche atrás? ¿Eso es lo que quieres? (MARINA saca un pañuelito y se seca una lágrima furtiva) ¿Quieres que salga fuera y me deje ganar por Alarcón? (...) ¡Y luego si te he visto no me acuerdo!... iMisión cumplida! El pobre gilipollas del Kid ha picado el anzuelo... Seguro que te ganas otro abrigo de pieles... ¿Cómo no me he dado cuenta antes? ¡Eres una puta callejera, como todas las demás!

MARINA. (Va hacia él) Gracias, Kid. Así será todo más fácil.

30. Cfr. Phyllis Zatlin, art. cit., p. 129. Sus representantes les han impuesto los nombres de "Kid" y "Marina", que aparecen en las acotaciones; para esta cuestión, véanse Anne Ubersfeld, op. cit., p. 17, y, desde otra perspectiva, Jorge Urrutia, "De la posible imposibilidad de la crítica teatral y de la reivindicación del texto literario", en VV. AA., Semiología del teatro, pp. 285 y ss. 
KID. ¡Basta de comedia! ¡Ganas me entran de darte un puñetazo y sacarte de cuajo esos dientes tan blancos... y esa lengua tan... esa lengua tan... ¡Dios mío, cómo he podido creer en ti por un solo instante!

MARINA. (Le mira fijamente. Coge impulso y le pega una enorme bofetada. KID queda anonadado) Te lo mereces (Se da la vuelta y va hacia la puerta. KID corre tras ella). (ENGV, p. 55)

El estallido violento rompe bruscamente el nivel de intimidad conseguido y la relación se transforma, como muestra nítidamente el uso del apelativo boxístico del púgil. Además, varía la perspectiva desde la que Enrique contempla lo acontecido al percibir los dientes y la lengua, en lugar de la mirada pura; así, adquiere conciencia de hallarse ante una ficción organizada con el único fin de convencerle. Pero la taxativa postura del púgil se desmorona ante la mirada y la bofetada de Marina, cargadas de efectismo.

Por tanto, la paradoja se antoja doble: de un lado, un elemento de teatralidad convence a Enrique de la autenticidad de Nieves y le hace desechar sus sospechas de presenciar sólo teatro, de manera que la ficcionalización convierte ante sus ojos la propia ficción en realidad. De otro lado, la aparente reafirmación de la franqueza de Marina no es sino una prueba más de su engaño ${ }^{31}$, según puede comprobar el espectador de la obra más adelante; sin embargo, Enrique nunca descubre esta falacia y muere -irónicamente- creyéndose liberado de todos los engaños de su entorno, pensando que ha procurado a Nieves la felicidad al obligar a su novio a firmar un contrato de compromiso matrimonial, sin conocer el alcance de la mentira:

MATEOS. (A MARINA en primer término ) ¡Has estado genial! (La besa. Ella seca el sudor de la frente con su pañuelo)

(...)

Todavía no me explico cómo has conseguido... Ni siquiera entiendo qué es lo que ha ocurrido... El asunto ese del contrato... ¿Qué le has dicho?

MARINA. Nada. Que eres un canalla, que me has dejado embarazada y que no te quieres casar conmigo.

MAteos. ¡Ja,ja, ja! ¿Así de sencillo?... Parece mentira... Eres maravillosa, de verdad... Me siento... me siento en deuda contigo. Pídeme lo que quieras.

MARINA. (Sin pensar) Quiero el supermirafiori. (ENGV, pp. 63-64)

El desnivel entre ambos personajes parece evidente: Kid se ha convertido en Enrique, pero Marina nunca ha sido Nieves ni quiso un padre para su hijo; sólo ha pedido un coche. Enrique, que pretendía "llamar las cosas por su nombre" (ENGV, p. 60), yerra al dirigirse a Nieves como tal, pues ésta sólo es una máscara de Marina.

31. Jesús Rubio, art. cit., p. 200, señala cómo la relación entre la mayor parte de los personajes se basa en el engaño. Nótese que Kid y Sony son los únicos que no tratan de ejercer activamente la mentira, aunque sí son alcanzados por las que los demás crean. 
Finalmente, el espectáculo boxístico que se desarrolla en el transcurso de la acción dramática constituye un nuevo elemento de metateatralidad; aunque el público no puede contemplarlo por acontecer fuera del espacio escénico, de él llegan las noticias por cauces sonoros y orales ${ }^{32}$. Mateos, al igual que los espectadores de Esta noche gran velada, conoce el resultado del combate por los ruidos, gritos furibundos, las cuentas del árbitro y el anuncio por la megafonía de la victoria de Kid (ENGV, pp. 7071); a continuación, Marina describe el desarrollo del combate que ha presenciado y Marcel informa de la airada reacción de Achúcarro (ENGV, p. 72). Esta manera de resolver la presentación de la velada permite ofrecer la simultaneidad de acciones entre el triunfo de Kid y la desesperación de Mateos intentando preparar a tiempo un nuevo contrato para el púgil. A la vez, coloca a Marina, Sony, Marcel y Achúcarro como actores de Esta noche gran velada y espectadores de la pelea; a Kid como protagonista de ambos espectáculos; y a Mateos en el mismo plano de conocimiento sobre el combate que tiene el público de la obra.

\section{De Fuiste a ver a la abuela??? a Caballito del diablo}

El teatro dentro del teatro stricto sensu aparece en Fuiste a ver a la abuela???, cuyo principio y final son idénticos: ambos repiten la escena del ensayo de una representación de un belén, si bien podemos observar algunas diferencias. En el primer caso se presenta un montaje infantil de la natividad de Jesús, en el transcurso del cual Miguel es despojado de su papel y vestidura de ángel en función de un criterio moral aplicado por don Raimundo ( $F A V$, pp. 79-80). En el segundo, el nacimiento se asocia a Antonio y a su hija Elisa, adquiriendo un tono profano subrayado por la creciente irreverencia del resto de los componentes de la escena, uno de los cuales ofrece "una botella de whisky" o "cinco mil pesetas", mientras que otro de los amigos de Antonio "era un camello y le traía una china, para que se la fumen sus papás" ( $F V A$, pp. 121122); además, la ficción no se ve interrumpida por un sacerdote que la reconduzca, sino que sigue, se repite y permanece hasta la caída del telón. La inversión es evidente: el tiempo ha pasado, se han desvanecido los valores de la infancia pero también los de la represión y la dictadura; ya no hay ángeles en escena.

Por otra parte, tanto esta obra como Caballito del Diablo basan su estructura en la secuenciación, en el fundido de escenas que disuelven la sucesión cronológica y lógico-causal de los acontecimientos, mientras la conexión entre aquéllas se produce

32. Sobre la oralidad como fuente de comunicación con el espectador, véase Bobes Naves, "Valor performativo...", p. 179. 
mediante asociaciones temáticas. Todo ello remite a técnicas cinematográficas muy caras a Cabal y explotadas por grupos teatrales independientes ${ }^{33}$.

Sin embargo, Caballito del diablo emplea un lenguaje dramático más fluido, que se fundamenta en la simultaneidad de decorados no corporeizados recreados a partir de la cama y el televisor como únicos elementos escenográficos junto con los luminotécnicos ${ }^{34}$. En esta clave, ya de por sí experimental, del espectáculo se debe insertar el uso de técnicas audiovisuales tales como los vídeos proyectados a través del televisor en la representación 35 ; tal recurso introduce un factor de reflexividad puesto que supone la presentación de unas imágenes enmarcadas en un aparato de televisión dentro del espacio escénico, lo cual multiplica los niveles de contemplación y de formas de comunicación dentro de la propia comunicación teatral.

La obra incluye alusiones a Hollywood en tanto lugar de confluencia de lujo, drogas y alcohol ( $C D$, p. 128). Asimismo, se reproducen frases míticas de guiones cinematográficos, como el célebre "si me necesitas silba" ( $C D$, p. 94), que remite inmediatamente a Bogart y al cine negro americano; así se introduce un fragmento de la ficción en el seno de otra -el discurso de Merche- y se vincula Caballito del diablo a un género cinematográfico donde se recrean corruptelas, suburbios y personajes autodestruidos por sus adicciones.

Por otra parte, adquiere un importante protagonismo el propio referente teatral desarrollado básicamente a partir de Teresa; de ella sabemos que "querría ser actriz"

33. Para el caso de Fuiste a ver a la abuela???, véase la reseña de Miguel Angel Medina en Primer Acto, 182 (1979), p. 186. El dramaturgo leonés incorpora el tiempo cinematográfico a la estructura dramática, salvando sus diferencias, señaladas por Jan Mukarovsky, "En torno a la estética del cine", en Escritos de estética y semiótica del arte, ed. de Jordi Llovet, Barcelona: Gustavo Gili, 1977, p. 213. La secuencia es una unidad sintáctica característica del cine, $c f r$. Christian Metz, "La gran sintagmática del film narrativo", en VV. AA., Análisis estructural del relato, Barcelona: Editorial Buenos Aires, 1982, p. 148; para las articulaciones de dicho lenguaje, véase Umberto Eco, La estructura ausente..., pp. 283, 285 y ss. El propio Fermín Cabal, "Historia y evolución de la estructura dramática", Primer Acto, 215 (1986) pp. 93 y 96, señala que lo específicamente dramático está a menudo contenido en otras expresiones artísticas, y destaca la incorporación de los valores plásticos al teatro gracias al empuje del cine. Para la veta de teatro que cultiva elementos visuales y de imagen en los últimos años, $c f r$. Luciano García Lorenzo y $M^{a}$ Francisca Vilches de Frutos, "Transición y renovación en el teatro español", Insula, 456-457 (1984) p. 16; dicha veta alimenta además gran parte del teatro independiente español coetáneo, como ha estudiado Vilches de Frutos, "El teatro español en los 80...", p. 14.

34. Cfr. la descripción del espectáculo realizada por el propio Cabal y las fotografías de la puesta en escena recogidas por José Luis Vicente Mosquete, art. cit., pp. 36-38. El montaje del grupo Tramoya potenció los esquemas estéticos inspirados en el lenguaje del cine, véanse Julio Rodríguez Blanco, "Casi diez años. Tramoya estrena a Fermín Cabal", El Público, 26 (1985) p. 46; y la Guía teatral de España 1985, Madrid: El Público, p. 98. El fundido de escenas y la simultaneidad de decorados, aislados como diferentes mediante la iluminación sucesiva de cada uno de ellos y el oscuro para el resto, reaparecen en Entre tinieblas, la función, reciente montaje teatral de Cabal a partir de la película de Pedro Almodóvar; no obstante, en este caso no se produce la referida disolución lógico-causal.

35. César Oliva, El teatro desde 1936, Madrid: Alhambra, p. 456, da escueta noticia de la utilización del recurso, que puede apreciarse en los testimonios gráficos citados supra, n. 34. 
$(C D$, p. 80$)$, y que rechaza inicialmente una oferta de trabajo en una película pornográfica $(C D$, p. 87). Por mediación de Blanca, interpreta un papel de protagonista femenina en un montaje de Romeo y Julieta de Shakespeare; si bien la inclusión de dicha referencia intertextual supondría un índice de metateatralidad por sí misma, ésta va a adquirir una funcionalidad pluridireccional que enriquece la obra de Cabal.

Tanto la labor artística de Teresa como la intensidad de estudio y ensayos sirven para poner de manifiesto el alejamiento afectivo entre ella y Celes, quien piensa que la ficción de la tragedia shakespeareana puede empujarla a buscar su Romeo en un compañero de compañía teatral $(C D$, p. 110). Además de conflictos amorosos, dicha compañía propicia la aparición del humor a partir de la figura del director teatral, Horacio Grillo: su apellido provoca los chascarrillos de Teresa ( $C D$, p. 93); de Celes, que lo califica de "grillao" ( $C D$, p. 101) en un juego paronomásico sobre la locura del director en su aventura teatral; e incluso de Blanca:

\author{
BlanCA. Tu amigo el Grillo. \\ MERCHE. ¿Qué grillo? \\ BlanCA. Uno que hace cri-cri. ( $C D$, p. 132)
}

La broma acerca a Teresa y su cuñada, pues aquélla había establecido idéntica asociación ante la primera oferta para participar en el espectáculo escénico; de esta manera, se confirma en el plano microtextual el progresivo desplazamiento que Blanca experimenta desde su vida convencional hasta la inmersión en la drogodependencia, siguiendo la vía marcada por Teresa en este aspecto y en la relación erótica con Celes.

La inserción de la tragedia en Caballito del diablo no sólo resalta las complejas relaciones entre lo ficticio y lo real; también propicia la formulación de una propuesta concreta que refleja una praxis teatral cercana a la de los grupos de carácter experimental o independiente:

TEResa. (...) Se lo quiere hacer de cooperativa...

Blanca. ¿Y sois muchos en el reparto?

Teresa. No. Romeo, Julieta y el Coro.

BlanCA. El cura quieres decir...

Teresa. El cura, la nodriza, el padre y la madre de Julieta, los Montescos, los Capuletos, su primo... Es un personaje coral. Sale cada vez con una máscara distinta y va haciendo todos los papeles... La idea no es mala, ¿eh?

BlanCA. Por lo menos es barata.

Teresa. El tío no es tonto... Tiene ideas... Va todo de baile y acrobacia, ¡nada de rollo retórico!... Yo creo que puede funcionar. ( $C D$, pp. 94-95)

El diálogo traduce las posibilidades de construcción dramática alternativa a partir de un texto clásico y un "tema eterno" $(C D$, p. 95$)$ como el de los amantes veroneses; 
de esta manera el texto teatral se considera abierto, desde su potencialidad intacta, a diferentes desarrollos escenográficos y conceptuales a lo largo de la historia ${ }^{36}$.

La propuesta de Horacio Grillo hace hincapié precisamente en el componente espectacular y teatral de la tragedia: establece una preponderancia de lo gestual y kinésico por encima de la palabra e introduce elementos de otras artes -como la danza- o incluso circenses; esta síntesis conecta a su vez con la revalorización de la espectacularidad y la pantomima llevada a cabo en los años veinte ${ }^{37}$. Asimismo, se transforma el propio componente metateatral de la tragedia Romeo y Julieta $^{38}$ fusionando a los personajes que acompañan a los amantes en uno único y coral, con lo que se confiere otro alcance a la sucinta aparición del coro en el texto inglés. Tales modificaciones pueden relacionarse con el replanteamiento de la función del coro en la tragedia clásica ${ }^{39}$; pero, sobre todo, con una técnica de disolución del mimetismo y potenciación del primitivismo teatral mediante la cual el solo trueque de una máscara permite la variación del papel, ya utilizada por el propio Cabal en Fuiste a ver a la abuela???40.

36. Richard Hornby, op. cit., pp. 93-94 y 101, analiza tales reinterpretaciones de la tradición teatral como adaptaciones, al tiempo que subraya el uso que de ella han hecho grupos vanguardistas y experimentales en el siglo XX. Y cfr. $\mathrm{M}^{\mathrm{a}}$ del Carmen Bobes, Semiología de la obra dramática, pp. 65, 67-69 y 72 .

37. Para este fenómeno, crucial en figuras como Meyerhold, véase Jean-Jacques Roubine, op. cit., p. 168; por su parte, André Helbo, "Código y teatralidad. Una lectura de Port Royal", en VV. AA., Semiología del teatro, p. 134, estudia el efecto de lo circense en el teatro. Jacques Derrida, "Le théâtre de la cruauté et la clôture de la representation”, en L'écriture et la différance, Paris: Seuil, 1967, pp. 345-347, analiza el destronamiento de la supremacía de la palabra en el caso de Artaud.

38. Recordemos sólo el juego de realidad y ficción implícito en los propios planes de Fray Lorenzo y Julieta ( $c f r$. William Shakespeare, Romeo y Julieta, ed. bilingüe del Instituto Shakespeare dirigida por Manuel Angel Conejero, Madrid: Cátedra, 1991, acto IV, 1, p. 345) que llevan a la fingida muerte de la joven, quien antes de tomar el bebedizo llega a dudar sobre la veracidad del plan o su falsedad (ibidem, acto IV, 3, pp. 355-357); Romeo, que cree auténtica dicha Ficción al no contar con el mensaje que le permitiría decodificarla correctamente, tras plantearse si es sueño o verdad lo que le dijo su criado sobre el desposorio de su amada con Paris, se suicida (ibidem, acto V, 2, pp. 397-401), lo que desencadenará a su vez la muerte de la protagonista (ibidem, p. 407). Nótese la diversidad de la tensión entre lo real y lo irreal, tema tan barroco y unido al problema de la apariencia teatral.

39. Manfred Schmeling, op. cit., p. 12, distingue la función del coro en la tragedia clásica y en el siglo XX; y véase Patrice Pavis, op. cit., s. v. coro. Cfr. Richard Hornby, op. cit., pp. 34-35, quien niega la auténtica naturaleza metateatral del coro, y lo estudia más en tanto convención capaz de producir extrañamiento (ibidem, pp. 35-36).

40. Para las posibilidades de la máscara teatral y su interrelación con el mimo y la pantomima, véase Georges Mounin, Introducción a la semiología, Barcelona: Anagrama, p. 204; Raúl Castagnino, Teorías sobre el texto dramático y la representación teatral, Buenos Aires: Plus Ultra, 1981, p. 123, considera los efectos de extrañamiento de dichos usos. No olvidemos que Meyerhold impulsó la tradición del actor enmascarado y pantomímico, cfr. Jean-Jacques Roubine, op. cit., p. 168. Recuérdese $F V A$, p. 105: "(Los danzantes van rodeando a ANTONIO cubriéndose con máscaras. ANTONIO se deja caer al suelo quedando en posición fetal rodeado por el resto)". En Fuiste a ver a la abuela??? la metateatralidad periférica (según la terminología de Manfred Schmeling, op. cit., p. 13) se desarrolla cuando un mismo actor, sin cambio 
METATEATRO Y RETEATRALIZACIÓN EN FERMÍN CABAL

Por otra parte, el montaje del drama shakespeareano va a interferir en las vidas de los personajes de Caballito del diablo hasta difuminar las fronteras entre el grado de realidad de esta última obra y la que se inserta en ella, y entre ambas ficciones en general. Celes pondera la irrealidad de la tragedia de los dos amantes:

CELEs. (Cogiendo el libreto) Esta obra es una pasada. La chica se mata, el Romeo se mete una sobredosis de pócima, y al otro le dan de cuchilladas... (Tira el libreto despectivo) ¡Esto no hay quien se lo crea! (CD, p. 101)

La historia que parà él es inverosímil resulta irónicamente una duplicación por un lado del desenlace trágico y auto-destructivo de su propia vida: a la pelea entre Paris y Romeo corresponde la de Celes y Marciano; éste, nuevo amante de Teresa, apuñala al rival indignado por el corte de la droga y celoso por la reciente promiscuidad de su novia ${ }^{41}$. A pesar de las diferencias ideológicas entre las dos piezas, ya que la degradación del universo de la de Cabal es patente, no parece descabellado establecer este paralelismo entre dos sucesos determinados por la muerte, el amor y ese destino devastador al que no se puede escapar: Celestino es un nuevo Paris que busca venganzc. y muere a manos de su rival; la ausencia de lo sublime amatorio en ambos no es óbice para que el peso anímico de la situación recaiga sobre Celes.

Asimismo, la relación entre los dos niveles de ficción dramática que percibe el espectador se torna mutua y circular, puesto que las vivencias de los personajes de Caballito del diablo pueden sugerir una modificación en el espectáculo shakespeareano:

TERESA. Me has dado una idea... ¿Qué tal si muere así Julieta? La chica se levanta del túmulo mortuorio y descubre a Romeo hecho polvo. ¡Entonces coge la droga, se la pica (Se apuñala en el brazo como si fuera una chuta) y cae diciendo... “¿Esta vez, sí!” (Cae) (CD, p. 106)

A su vez, dicho cambio en la tragedia duplica perfectamente la muerte de Blanca y el desenlace de la ficción donde se inserta:

SANDOKAN. ¿Qué raro! Hacía tiempo que no me pasaba... Ten cuidado, no te metas mucho. Si hace tiempo que no te picas (...) (BLANCA suelta el brazo y

\footnotetext{
alguno de vestuario o escena, pasa a interpretar un personaje distinto ( $F V A$, pp. 87-88 y 105); tal deslizamiento no se produce arbitrariamente, sino en el seno del "rol común" estudiado por Anne Ubersfeld, $o p$. cit., pp. 81-83. Para una visión de conjunto de las clases, funciones y posibilidades del personaje dramático, véase Solomon Marcus, "Stratégie des personnages dramatiques", en VV. AA., Sémiologie de la représentation, pp. 73-89.

41. Discrepo de la interpretación de Phyllis Zatlin, art. cit., p. 130, quien entiende que Celestino muere de una sobredosis; véase $C D$, p. 130: "(El MARCIANO se levanta aturdido y saca una navaja. CELES aparta a TERESA. El MARCIANO se tira sobre CELES y le mete la navaja en la tripa)". El enfrentamiento al que aludo en la tragedia británica puede verse en Romeo y Julieta, acto V, 2, pp. 395-397.
} 
dobla la cabeza lentamente. La chuta le queda colgando) ¡Blanca! (SANDOKAN va hacia ella) ¿Qué te pasa? (La sacude) ¡Blanca! ¡Blanca! ¿Me oyes?

BLANCA. (Haciendo un gran esfuerzo) Sandi...

SANDOKAN. ¿Qué?

BlanCA. Esta vez, sí... (CD, pp. 134-135)

Teresa representa la muerte de Julieta incorporando a tal desenlace lo acontecido en la de Chuck, de modo que dicha versión transforma en parte el sentido último de la tragedia isabelina; al mismo tiempo, el despliegue de teatralidad de la actriz provoca en los que la contemplan el mismo efecto distanciador que ella había procurado. La reflexividad de la secuencia se antoja patente considerando la multiplicación de niveles mostrada simultáneamente en Teresa -personaje del texto de Cabal-, actriz que desempeña el papel de Julieta en un montaje experimental de la obra inglesa y que introduce cambios en el momento más climático de la misma en función de la historia de Chuck; otra vuelta de tuerca se añade al complejo mecanismo cuando dicha modificación genera una escena que coincide precisamente con otra de Caballito del diablo, la de la muerte de Blanca.

La sobredosis que acaba con su vida debe enmarcarse en el encuentro de Sandokán, quien la ama y la acompaña en el camino que la arrastra hacia la droga nuevamente. Un amor límite y la fuerza de un destino que no se sabe ni puede eludir confieren la tensión dramática a la citada escena; tales elementos coadyuvan a la equiparación con el drama isabelino, y a la de Blanca con una moderna -aunque distintaJulieta.

Pero la inclusión del teatro shakespeareano todavía se extiende más allá del texto aludido:

Celes. La Blanca no es un yonqui... Es un mercader.

TERESA. Sí, el mercader de Venecia.

NENA. ¿Qué?

TERESA. Cosas mías... ( $C D$, p. 116$)$

Precisamente Teresa, actriz ligada a Shakespeare a través de su papel de Julieta, pronuncia una frase cuyo referente en la obra homónima abre al público multitud de sugerencias: el universo interior que el espectador posee como receptor de teatro puede llevarle a evocar cómo Porcia finge ser doctor en leyes para salvar a Antonio, o incluso a contrastar la evolución personal de Blanca con la personalidad de aquél -indiferente ante los propios riesgos económicos y amigo fiel-42. La alusión de Teresa

42. Cfr. William Shakespeare, The Merchant of Venice, ed. de John Russell Brown, London: Methuen \& Co, 1972, acto IV, para el caso de Porcia. Antonio formula el topos del theatrum mundi al declarar su estatuto de actor en un mundo que sólo es representación: "I hold the world but as the world Gratiano,/ A stage, where every man must play a part,/ And mine a sad one" ( ibidem, acto I, 1, p. 8). 
adquiere una dimensión irónica tanto por su contexto inmediato como por el hecho de que la pronuncie quien cree de Blanca que ésta no es sino una actriz que va "de buena por la vida" y sin embargo es "más buitre que nadie" ( $C D$, p. 126).

Al margen del grado de adición significativa aportada por la citada frase, su auténtica productividad reside en su carácter intertextual abierto, el cual posibilita la participación activa y reflexiva de cada receptor ${ }^{43}$; así, las interpretaciones se individualizan y el espectador capaz de captar la referencia shakespeareana puede cotejar las diferencias de su comprensión respecto de Nena, Rosco y Celes, quienes no perciben dicha alusión.

Aún cabe considerar el plano de complejidad que añade la novela escrita por Blanca, texto literario que anticipa, prefigura y duplica el final del drama donde ella misma muere de una sobredosis:

BlanCA. Estoy en otro rollo, Merche... Nada que ver. He empezado a escribir una novela. Se titula Caballito del diablo. ¿Te gusta?

MERCHE. ¡Mmm! ¿Y de qué va?

Blanca. Pues de qué va a ir. Del ambiente. De lo que me pasa. De lo que se me ocurre. Es la historia de una tía que está hasta el coño de todo se mete una sobredosis y mientras se prepara la chuta, va recordando... La historia empieza cuando era pequeña y se escapaba para ir a jugar al estercolero de su abuelo... (CD, pp. 122-123)

Efectivamente, el comienzo de la pieza de Cabal coincide con el que Blanca ha asignado a su relato ( $C D$, p. 85); así, se refuerza el estatuto ficticio de Caballito del diablo, que es teatro en un primer nivel y literatura al equivaler al relato que Blanca ha creado a partir de sus experiencias. Por otra parte, la técnica retrospectiva de la narración apunta a la organización de la obra en desorden lógico-causal, con un hilo conductor basado en asociaciones temáticas o de personajes. Las fronteras entre lo ficticio y lo real quedan totalmente difuminadas en un texto dramático como éste, cuyo final es idéntico al que Teresa crea para Romeo y Julieta adaptando la muerte real de Chuck, a la vez que está ya escrito en la novela de Blanca.

Paralelamente a lo expuesto, los personajes presentan una clara conciencia del fingimiento implicado por la vida: Blanca cambia la hipócrita "comedia" de su rutinaria asistencia al trabajo a diario por el "drama" $(C D$, p. 100) en que están sumidos los drogadictos marginados, quienes no participan de la representación aceptada por la sociedad. Villanos, buenos o buitres ${ }^{44}$, todos participamos de un papel elegido o impuesto.

43. Manfred Schmeling, op. cit., p. 49, estudia esta llamada a la incorporación del saber individual de cada miembro del público. Y cfr. Umberto Eco, Obra abierta, passim.

44. Cfr. las palabras de Teresa: "No me hagas reír, Blanquita. Tú de tonta no tienes un pelo. Vas de buena por la vida y le dejas a los demás el papel de villanos en la función. Pero eres más buitre que nadie. Te lo quieres tragar todo: el caballo, el dinero, el Celes..." (CD, p. 126). 
De esta manera, tanto temas eternos de la vida o la literatura como conflictos concretos de la realidad coetánea española y europea ${ }^{45}$ son planteados nuevamente por Cabal en este complejo entramado de metateatralidad. El gran hallazgo de Caballito es la polifuncionalidad del elemento intertextual, que propende a generar un entremezclamiento de niveles donde las diversas ficciones interactúan, mientras se replantea la puesta en escena de Romeo y Julieta.

Parece lícito sostener la profunda raíz teatralista de la dramaturgia de Fermín Cabal, puesto que su conciencia autorreflexiva incide en la hiperbolización o reduplicación de los elementos de cada obra. Los recursos utilizados varían: la exacerbación de la gestualidad y del movimiento escénico en las obras cercanas a lo farsesco como Tú estás loco, Briones y Vade retro!; o la ruptura de cualquier ilusión de mimetismo y la búsqueda de otras formulaciones teatrales en Fuiste a ver a la abuela??? y Caballito del diablo. Vehículos de metateatralidad como la periférica ruptura del rol o la implicación del público en el espacio dramático ( $V R$, p. 134 y $F V A$, p. 96) confluyen en una particular concepción del hecho escénico.

La trabazón artística de la creación del autor se enriquece a partir de Esta noche gran velada, donde la multiplicidad de planos superpuestos configura una visión del mundo y del propio teatro más matizada: ya no bastan una pirueta o una reacción desmesurada, porque el avance de la obra se acompasa con el descubrimiento al espectador de artificios que ponen en cuestión las fórmulas de la vida cotidiana y del espectáculo dramático.

Los niveles de la realidad y la irrealidad se entremezclan en un continuo desvelamiento de apariencias que ocultan a su vez nuevas falacias, en una huida de la mentira hacia la autenticidad; mientras, esa representación de la representación encarnada por algunos personajes y situaciones muestra con nitidez no ya lo real -que también ha perdido su sentido-, sino lo verdadero.

45. Wilfried Floeck, "Ist Spanien anders? Zur Problematik ausländischer Kulturrezeption am Beispiel des modernen spansichen Theaters", en VV. AA., Spanisches Theater im 20. Jahrhundert..., p. 13. 